\title{
Factores que predicen el riesgo de los derechos de los menores en el uso de redes sociales
}

\author{
Factors that Predict the Risk of Minors' Rights in the Use of Social Networks
}

\section{Fatores que preveem o risco de direitos de menores no uso de redes sociais}

\author{
Carlos René Contreras Cázarez \\ Universidad de Sonora, México \\ renecazarez@gmail.com \\ https://orcid.org/0000-0001-8538-6544
}

\section{Resumen}

La tecnología digital ha trastocado la vida de los niños y niñas; ahora viven en un mundo más conectado, lo que ha generado grandes ventajas, como el libre acceso a la información, pero también grandes riesgos, situaciones que atentan contra los derechos particulares de los menores. El presente artículo persigue el objetivo de describir y analizar los hábitos de consumo en redes sociales de estudiantes de educación primaria teniendo en cuenta sus derechos fundamentales. Con una metodología de corte cuantitativo y enfoque hipotéticodeductivo, la investigación aspira a identificar a través de un modelo estructural los derechos de los niños y niñas que están siendo afectados por el consumo habitual de redes sociales que realizan los propios infantes mediante dispositivos móviles. Se empleó una muestra de 290 alumnos de $5 .^{\circ}$ y $6 .^{\circ}$ año de escuelas primarias públicas en la localidad de Hermosillo, Sonora, México. Como parte de los resultados, se exponen las medidas de tendencia central: media, mediana y desviación estándar de variables demográficas, el alfa de Cronbach de las escalas empleadas, así como los índices de bondad de ajuste y ji al cuadrado del modelo propuesto para el estudio. Las diversas pruebas evidencian una fuerte predisposición a afectar 
y vulnerar algunos derechos fundamentales de los menores en la era digital a partir de sus hábitos de consumo.

Palabras clave: derechos, dispositivos móviles, menores, redes sociales, riesgos.

\section{Abstract}

Digital technology has disrupted the lives of children; they live now in a more connected world, with great advantages such as free access to information, but also great risks, situations that threaten the particular rights of minors. This article aims to describe and analyze consumer habits in social networks in primary school children associated with their fundamental rights. With a quantitative cut methodology and hypothetical-deductive approach, the research aims to explain through a structural model the rights of children who are being affected by their habits of use and consumption of social networks through mobile devices. A sample of 290 students from $5^{\text {th }}$ and $6^{\text {th }}$ year of public elementary schools in the town of Hermosillo, Sonora, Mexico was used. As part of the results, measures of central tendency are exposed: mean, median and standard deviation of demographic variables, Cronbach's alpha of the scales used, as well as the indexes of goodness of fit and the Chisquare of the model proposed for the study. The various tests show a strong predisposition to affect and violate some fundamental rights of minors in the digital age based on their consumption habits.

Keywords: rights, mobile devices, minors, social networks, risks.

\section{Resumo}

A tecnologia digital interrompeu a vida das crianças; agora eles vivem em um mundo mais conectado, o que gerou grandes vantagens, como livre acesso à informação, mas também grandes riscos, situações que ameaçam os direitos particulares dos menores. O presente artigo tem como objetivo descrever e analisar os hábitos de consumo de alunos do ensino fundamental nas redes sociais, levando em consideração seus direitos fundamentais. Utilizando uma metodologia quantitativa e uma abordagem hipotético-dedutiva, a pesquisa tem como objetivo identificar, através de um modelo estrutural, os direitos das crianças afetadas pelo consumo habitual de redes sociais pelas próprias crianças que usam dispositivos móveis. Utilizou-se uma amostra de 290 alunos do $5^{\circ}$ e $6^{\circ}$ anos de escolas primárias públicas 
da cidade de Hermosillo, Sonora, México. Como parte dos resultados, são expostas as medidas de tendência central: média, mediana e desvio padrão das variáveis demográficas, o alfa de Cronbach das escalas utilizadas, bem como os índices de qualidade de ajuste e quiquadrado do modelo proposto para o estudo. estude. Os vários testes mostram uma forte predisposição para afetar e violar alguns direitos fundamentais dos menores na era digital com base em seus hábitos de consumo.

Palavras-chave: direitos, dispositivos móveis, menores, redes sociais, riscos

Fecha Recepción: Junio 2019 Fecha Aceptación: Enero 2020

\section{Introducción}

Internet y las tecnologías de la información y comunicación (TIC) son herramientas que avanzan de manera acelerada. A causa de la proliferación y diversificación de estos instrumentos, se han instaurado nuevas estrategias que posibilitan la comunicación y abonan a los procesos de interacción. Para Gallego (2011, citado en González, 2014), el proceso de interacción social "ha ido evolucionando a lo largo del tiempo hacia una forma de estructura más compleja, de ahí la aparición de las redes sociales con el resultado principal: la continuidad de los grupos humanos" (p. 114). En este sentido, las redes sociales virtuales permiten la interacción mediante un medio tecnológico con conexión a Internet, “donde las personas comparten y publican todo tipo de información, personal y profesional, con terceras personas, conocidos y absolutos desconocidos” (Celaya, 2008, citado en Hütt, 2012).

Según el Fondo de las Naciones Unidas para la Infancia [Unicef] (2017), aunque han traído a los niños contenido enriquecedor, nuevas experiencias de aprendizaje y la posibilidad de explorar amistades de formas antes no vistas, las TIC también "han amplificado los peligros tradicionales (como por ejemplo la intimidación) y creado nuevas formas de abuso y explotación infantil" (p. 4).

Al ser una investigación que estudia y analiza a menores (niños y niñas), es propicio brindar algunas definiciones puntuales que aclaren por qué esta población es considerada de riesgo. Espinosa (2000, citada en Pérez, 2005) define a los grupos o comunidades vulnerables de la siguiente manera: 
Aquellos que, por circunstancias de pobreza, origen étnico, estado de salud, edad, género o discapacidad, se encuentran en una situación de mayor indefensión para hacer frente a los problemas que plantea la vida y no cuentan con los recursos necesarios para satisfacer sus necesidades básicas (párr. 8).

La Comisión Económica para América Latina y el Caribe [Cepal] y la Unicef (2014), cuando definen el concepto de infancia, afirman que no refiere al preámbulo de la vida adulta, es una etapa que tiene valor en sí misma y los niños deben ser aceptados y protegidos como sujetos de derecho. Así lo entiende la comunidad internacional y es la base sobre la que está construida la Convención sobre los Derechos del Niño (Unicef, 2006).

La propia Unicef (2014) también aporta a la conceptualización de vulnerabilidad:

La edad, la discapacidad, la enfermedad, el género, la pertenencia étnicocultural, etc. son situaciones o características de los sujetos que coadyuvan a su mayor o menor vulnerabilidad según como se relacionen con otras variables $y$, en general, con el contexto económico, político y cultural en el que se integran (p. 18).

Una vez identificada nuestra población objetivo como grupo de riesgo, se hace la aclaración de que a lo largo del presente estudio se referirá a este colectivo como menores, etapa de infancia intermedia, niños y niñas. Así pues, esta investigación tiene como propósito central describir y analizar los hábitos de consumo en redes sociales de un grupo de menores de educación primaria teniendo en cuenta sus derechos fundamentales. Adicionalmente, el texto aspira a explicar a través de un modelo estructural los derechos de niños y niñas que están siendo afectados por sus hábitos de uso y consumo en redes sociales mediante dispositivos móviles.

\section{Prevalencias de la población objetivo}

Según la Cepal (2014, citada en Sánchez y Robles, 2016), Internet es usado por niños y adolescentes sobre todo para obtener información y comunicarse; en concreto: desde buscar contenidos relevantes para sus estudios hasta socializarse (en diferido o en tiempo real), visitar las redes sociales, descargar música, películas y entretenerse con videojuegos en línea. En el contexto europeo, particularmente en España, según el Instituto Nacional de Estadística [INE] (2019), $92 \%$ de los menores de 10 a 15 años son usuarios de Internet. Como se puede constatar, la utilización de las nuevas tecnologías por parte de esta población en España se 
encuentra, en general, muy extendida. El uso de ordenador es muy elevado (lo tienen $89.7 \%$ de los menores) y aún más el uso de Internet (92.9\%). Por su parte, $66.0 \%$ de la población de 10 a 15 años dispone de teléfono móvil (INE, 2019).

La situación en México es similar a lo que ocurre en otros países. El Instituto Nacional de Estadística y Geografía [Inegi] (15 de mayo de 2019) para el 2019 reportó 74.3 millones de usuarios en México y 18.3 millones de hogares con acceso a Internet, con base en la Encuesta Nacional sobre Disponibilidad y Uso de Tecnologías de la Información en los Hogares (Endutih) aplicada a finales del año 2018. En el mismo informe, según los menores encuestados de seis años o más en el país, 74.3 millones declararon sí usar Internet (65.8 \% de la población). Esta cifra significa un avance de $1.9 \%$ respecto de los datos de 2017 (63.9 \%). La población objetivo indicó que $73.5 \%$ es usuaria de teléfono celular (habilitado para hacer y recibir llamadas o mensajes). De ellos, $83.8 \%$ cuenta con al menos uno de los llamados teléfonos inteligentes o smartphone; $0.8 \%$ cuenta con al menos un celular común y un celular inteligente a la vez, y $15.4 \%$ únicamente cuenta con al menos un celular común (Inegi, 15 mayo de 2019).

En un par de investigaciones realizadas al norte de México por León, Caudillo, Contreras y Moreno $(2014,2015)$ se evidenció que durante los periodos 2013-2014 y 20142015 los jóvenes de entre 12 y 15 años de edad accedían a Internet a través de dispositivos móviles entre $83 \%$ a $84.5 \%$; cabe señalar que entre cada diagnóstico se incrementó poco menos de $1.5 \%$. Ahora bien, en este mismo contexto mexicano, el estudio presentado por Contreras (2019c) evidenció a través de un modelo estructural una tendencia de acceso y consumo de Internet en menores con fines de socialización. Los datos descriptivos del estudio revelaron que más de $90 \%$ de los menores encuestados utiliza la telefonía celular inteligente para sus procesos de socialización e interacción con sus iguales (Contreras, 2019c).

Teniendo en cuenta todo lo anterior, la finalidad que persigue el presente estudio es describir y analizar los factores que predicen el riesgo asociado a los derechos fundamentales de los menores en el proceso de socialización por redes sociales a través de dispositivos móviles. Como añadidura, un eje central de la investigación aspira a explicar por medio de un modelo estructural las variables que influyen en la conducta de los menores en el mundo digital y que están vinculadas con la vulneración de algunos de sus derechos fundamentales. Una vez que se ha establecido el objetivo de la presente investigación, se definen brevemente 
los factores que intervienen en el estudio y en el modelo estructural a partir de las aportaciones de diversos campos disciplinarios y referentes teóricos.

\section{Socialización. Una definición desde las ciencias sociales}

El proceso de socialización ha constituido uno de los principales objetos de estudio de las ciencias sociales. Sus aportaciones devienen desde diferentes enfoques conceptuales y metodológicos (Simkin y Becerra, 2013). Desde la perspectiva académica, sociabilidad es un concepto que tiene sus orígenes en los estudios sociológicos, entre los que se destacan los realizados por autores como Georg Simmel, Max Weber y Georges Gurvitch (citados en Chapman, 2015). Para Simkin y Becerra (2013), la socialización puede ser entendida como el proceso mediante el cual los individuos incorporan normas, roles, valores, actitudes y creencias a partir del contexto sociohistórico en el que se encuentran insertos.

Otra definición del mismo campo disciplinar parte de la idea general, según Lucas (1986), de la socialización como proceso por el que un individuo se hace miembro funcional de una comunidad, a través del cual adquiere la cultura que le es propia. En otras palabras, la noción de socialización se puede definir como un proceso de adquisición de la cultura. Algunas otras aproximaciones teóricas definen a esta como un proceso de interacción donde confluyen características individuales, la cultura, la comunidad, las instituciones y el ambiente inmediato de desarrollo del individuo (Campa y Contreras, 2018). En palabras de Hernández y Alcoceba (2015), la socialización para los menores es percibida como el elemento integrador para la construcción de la identidad personal y grupal de los adolescentes. En ese sentido, dicha concepción sugiere la interacción de diferentes agentes individuales, grupales y sociales, entre los cuales se encuentra la familia, los grupos de amigos o pares, la escuela, así como los medios de comunicación.

Cuando se habla de socialización virtual o socialización en línea, se hace referencia a los procesos de interacción por medio de actividades de comunicación que se caracterizan por personas que interactúan y se encuentran vinculadas unas con otras de distintas formas; se relacionan con familiares, amigos, vecinos, compañeros, colegas y otros (Pacheco, Lozano y González, 2018). Bajo esta perspectiva, los jóvenes aprenden de sus amigos y coetáneos las conductas que la sociedad recompensa y los roles que pueden adoptar. En consecuencia, es posible afirmar que con "la llegada de Internet se han modificado las condiciones tradicionales para la constitución de la identidad. Ya no está presente la interacción física, lo 
que significa que las personas interactúan entre sí de manera no presencial" (Pacheco et al., 2018).

\section{Derechos de los menores en la era digital}

Los derechos fundamentales son ordenamientos que buscan la estabilidad de los individuos más allá de las nacionalidades. Cada país emprende políticas públicas para buscar el desarrollo y conservación de los derechos de sus habitantes. La Unión Interparlamentaria y la Organización de las Naciones Unidas [ONU] (2016) definen a los derechos humanos como "la suma de derechos individuales y colectivos reconocidos por los Estados soberanos y consagrados en su legislación nacional y en las normas internacionales de derechos humanos" (p. 20).

En esa línea, la Conferencia Mundial de los Derechos Humanos realizada en Viena en 1993 (citada en Fernández, 2016) señala que "deben reforzarse los mecanismos y programas nacionales e internacionales de defensa y protección de los niños y niñas" (p. 378). Al mismo tiempo, resulta innegable que, con el uso de Internet y con el apoyo de las tecnologías, se ha contribuido significativamente al desarrollo de los derechos humanos y se ha difundido el conocimiento: ahora está al alcance de sectores de la población mundial a los que antes les estaba imposibilitado. Sin embargo, el acceso a las tecnologías, y el Internet particularmente, ha traído consigo una serie de situaciones y circunstancias que transgreden y vulneran los derechos fundamentales de los menores de edad.

Algunas organizaciones gubernamentales y especialistas en el tema han coincidido en que los derechos de la niñez en la era digital deben formar parte de la agenda global. Lo anterior debido a que el desarrollo y ambiente social de un infante no se reduce solo a su dinámica física, sino también a las conductas y experiencias que suscitadas en línea (Unicef, 2014). Por tanto, Internet como tal puede ser una herramienta de ayuda en la protección y el acceso a otros derechos humanos, así como contribuir al crecimiento económico, social y político, y beneficiar a la humanidad en su conjunto (Fernández, 2016). Pero también se debe ser consciente de los efectos negativos que trae consigo, sobre todo en el ámbito de los derechos fundamentales del menor de edad, por lo que es necesario enfatizar en que se requieren mecanismos en cada país para que la población pueda denunciar contenidos que muestren abusos y explotación, con el fin de proteger y preservar los derechos de los menores (Unicef, 2016). 
De acuerdo con Fernández (2016), el acceso a la información e Internet, si bien es un derecho universal, puede afectar a los menores en relación con los contenidos que pueden circular por este medio mientras navegan en solitario. Entrelazado con lo anterior, la libertad de expresión se encuentra igualmente reconocida en la mayoría de las constituciones, no solo en Europa, sino también en Latinoamérica y Estados Unidos. El Convenio de Roma de 1950 (citado en Fernández, 2016), en su artículo 10, establece que toda persona tiene derecho de expresar y difundir libremente los pensamientos, ideas, y opiniones, así como a comunicar y recibir información a través de cualquier medio de difusión; situación que puede llegar a vulnerar los derechos fundamentales de los menores.

Si en Internet no existen garantías suficientes para ofrecer un entorno seguro que permita a los niños y niñas beneficiarse de las grandes ventajas que les puede proporcionar esta herramienta, puede ocurrir que se establezcan trampas en línea con la finalidad de explotar a los usuarios con fines delictivos. Entre estos, los más vulnerables a esas trampas son los niños. Los riesgos para los menores y el abuso de estas tecnologías siguen existiendo y, con la evolución de la tecnología y de los comportamientos sociales, aparecen nuevos riesgos y abusos (Fernández, 2016, p. 397).

\section{Hábitos de consumo: acceso y uso}

La Real Academia de la Lengua (s. f.) define al hábito como "modo especial de proceder o conducirse, adquirido por repetición de actos iguales o semejantes, u originado por tendencias instintivas”. En una definición más puntual de hábito de consumo, Mejía y Arboleda (2004) mencionan que es una acción que se realiza de manera constante y que, para el caso del consumo, se identifica a partir de lo que se acostumbra a adquirir y lógicamente a consumir. Por su parte, Douglas e Isherwood (1996, citados en Contreras y Campa, 2017) afirman que el consumo debe entenderse dentro del proceso social como parte de las necesidades de la gente de relacionarse entre sí, así como parte de la necesidad de mediadores materiales en esas relaciones.

Para otros autores, el uso, en un sentido más amplio, engloba todos los aspectos de acceso y utilidad que los adolescentes hacen de los medios de comunicación. Por su parte, Bringué, Sádaba y Rodríguez (2008) señalan que cuestiones como el equipamiento tecnológico en los hogares de los usuarios, el lugar de acceso a los diversos medios, el 
momento del día en el que los utilizan o la cantidad de tiempo que les dedican son algunos de los indicadores principales para medir los hábitos de consumo de Internet.

En un sentido más estricto, el uso es analizado y entendido, según Bringué y Sádaba (2010), a partir del equipamiento y acceso a los dispositivos tecnológicos, actitudes de consumo (tiempo dedicado, tipos de uso, lugares, compañía), así como el papel que desempeñan en el hogar y escuela. Mientras que Muñoz y Antón (2017) afirman que el acceso y uso de contenidos digitales ha de ser entendido en el contexto global de la sociedad de la información, donde Internet tiene una presencia constante y ubicua, y donde el ocio, el aprendizaje en la educación, así como lo laboral se relacionan estrechamente. Los usos de estos contenidos están sustentados y mediados por las TIC y por los valores de esta era de la información, postindustrial y de consumo, donde resulta difícil desvincular lo digital de Internet (Muñoz y Antón, 2017).

Por último, Contreras y Campa (2017) manifiestan que uno de los principales indicadores para analizar el acceso y uso de Internet son las redes sociales. De acuerdo con estos autores, las múltiples plataformas y aplicaciones de redes sociales se están convirtiendo día a día en el principal mecanismo de relación y socialización entre los consumidores. De hecho, el uso de redes sociales ha crecido de forma notable según los estudios analizados, y se ha situado como una de las principales vías de acceso para el consumo de contenidos, espacio para la interacción y la construcción de la identidad social de sus iguales, en ocasiones sin ningún control o supervisión parental (Bernal y Angulo, 2012).

\section{Método}

El presente estudio se abordó desde el paradigma positivista y se fundamenta en el enfoque racional, el cual se emplea para la recolección de datos "con base en la medición numérica y el análisis estadístico” (Hernández, Fernández y Baptista, 2010). La investigación es de tipo descriptivo-correlacional. Así, además de especificar propiedades y características de los factores analizados, es posible establecer correlaciones entre estos. Se utilizó un diseño no experimental de tipo transeccional, por lo que las variables del presente estudio se analizaron en su contexto natural, sin la manipulación deliberada, y en un momento único de recolección de datos: el periodo 2019-2020. 


\section{Población y sujetos del estudio}

La población la constituyen estudiantes de escuelas primarias públicas en Hermosillo, Sonora, México. La Unidad de Transparencia de la Secretaria de Educación y Cultura y servicios educativos del Estado de Sonora compartió las cifras de estudiantes matriculados de nivel primaria a partir de una solicitud de información en línea en su portal. La Secretaría de Educación y Cultura (SEC), para el año 2018, proporcionó el dato de que hay un total de 25779 alumnos inscritos en primarias públicas en Hermosillo, Sonora, México. La muestra total de los entrevistados bajo estudio a los que se les autoadministró el instrumento de recolección de datos está constituida por 290 estudiantes de educación básica y forman parte de los grados de $5 .^{\circ}$ y $6 .^{\circ}$ de educación primaria en Hermosillo, México.

Según datos del Inegi (2018), el estado de Sonora es la entidad con mayor conectividad en los hogares en el país, lo cual hace a la ciudad de Hermosillo idónea para aplicar el cuestionario, pues la probabilidad de acceso a Internet son altas. Por tal razón, los criterios para la selección de los participantes fueron los siguientes: ser estudiantes con habilidades básica digitales, tener acceso a Internet en el hogar y contar con algún dispositivo móvil (tableta o celular).

\section{Descripción del instrumento}

Se elaboró un instrumento cuantitativo con 66 reactivos conformado por tres escalas: Socialización, Hábitos de consumo y Derechos fundamentales. Las primeras dos escalas se adaptaron de una investigación más amplia sobre hábitos de consumo en Internet, competencias digitales y sociabilidad en línea en jóvenes (Contreras y León, 2019; León et al., 2014, 2015); mientras que la escala Derechos fundamentales se retomó de un estudio también más extenso donde se analizan los derechos fundamentales del menor de edad, la comunicación familiar, la confianza y el uso de redes sociales (Contreras, 2019b).

La escala Hábitos de consumo (acceso y uso) del instrumento de León, Contreras y Moreno (2016) conformada por 21 ítems fue implementada para medir todo lo relacionado al equipamiento de los menores en relación con dispositivos tecnológicos y móviles en el hogar, además de medir el acceso a los diversos contenidos y el uso que le dan a Internet, tal y como acceso involuntario a páginas con contenido potencialmente nocivos - no apropiados para menores de edad, por ejemplo: pornografía, violencia y situaciones de humillación hacia otras personas o hacia uno mismo; así como contenidos diversos de 
comportamientos socialmente no aceptables como el racismo y la xenofobia, ciberbullying o acoso sexual en Internet-.

Otra de las escalas que integra el instrumento es Socialización, y está conformada por 25 ítems. Incluye indicadores de hábitos de consumo en el uso de las redes sociales por parte de los menores, la frecuencia con que las utilizan, con quién las utilizan y para qué las utilizan (Contreras, 2019c). Adicionalmente, esta escala mide los diversos espacios que los menores emplean para la interacción virtual, los sistemas de comunicación que utilizan entre ellos mismos, con sus padres, personas conocidas y desconocidas, así como los posibles riesgos en sus procesos de socialización.

La escala denominada Derechos fundamentales se moldeó a partir de 20 reactivos y analiza cómo los menores perciben sus derechos fundamentales, tales como: acceso a la información, libre expresión y asociación, protección a la intimidad, así como el involucramiento y conocimiento de los padres o tutores en la digitalización y protección de los menores contra el abuso (Contreras, 2019a).

Para cada uno de estos ítems, los menores debían responder al instrumento con base en una escala Likert con cinco alternativas de respuesta, donde $1=$ Nunca, $2=$ Rara vez, $3=$ Algunas veces, 4 = Casi siempre y $5=$ Siempre. Así pues, para medir la confiabilidad y validez del instrumento, se calcularon los alfas de Cronbach para cada una de las escalas que componen al instrumento.

\section{Trabajo de campo}

Se seleccionaron dos centros de educación primaria en la ciudad de Hermosillo (México), ubicados en una zona de nivel socioeconómico medio. Una vez seleccionadas las instituciones, se envió una carta a los directivos de cada centro donde se les informó detalladamente el objetivo y pertinencia de realizar la investigación en dicho centro educativo. Acto seguido, se programó una cita con los directores de cada escuela para explicarles con mayor detenimiento el estudio a realizar. Con la finalidad de preservar los derechos de los menores, el instrumento fue revisado y aprobado por los directivos de las diferentes escuelas de educación primaria entre marzo y abril de 2019. Una vez obtenienda la autorización de las diversas escuelas primarias, se acudió nuevamente a estas para solicitar el apoyo a los profesores de aula para aplicar el cuestionario durante el mes de mayo de 2019. Posteriormente, se procedió a dar una breve explicación a los estudiantes del objetivo que 
persigue el proyecto, y se les pidió de su apoyo para responder con total confianza el instrumento. Se les advirtió tanto a profesores como estudiantes del tiempo estimado para responder el cuestionario; el tiempo fue entre 35 y 45 minutos, aproximadamente.

\section{Procesamiento y análisis de los datos}

La información recabada se sometió al programa estadístico SPSS, versión 23. Se evaluó la consistencia interna de cada uno de los factores a través del coeficiente alfa de Cronbach. Se obtuvieron estadísticas univariadas de tendencia central: mínimo, máximo, media, desviación estándar (ver tabla 1). Una vez hecho el análisis de confiabilidad de las escalas, se realizó el análisis de correlaciones de Pearson (Lloret, Ferreres, Hernández y Tomás, 2014). Se procedió al análisis mediante la prueba de esfericidad de Barlett y el índice de Kaiser-Meyer-Olkin (KMO) para examinar su idoneidad y ver en qué medida se relacionan dichas escalas. Tanto la prueba de esfericidad de Barlett como la medida de adecuación de KMO mostraron que los datos fueron adecuados (ver tabla 2); por lo que se procedió a realizar el análisis factorial exploratorio (AFE) y el análisis factorial confirmatorio (AFC); fue posible analizar los índices de bondad de ajuste, con el programa EQS versión 6.2, para corroborar que el modelo propuesto obtenido a partir del AFE y del AFC era consistente y adecuado. Como añadidura, se contrastó la relación de las escalas con un modelo estructural propuesto para el estudio (ver figura 1).

\section{Resultados}

La muestra total fue de 290 estudiantes de educación primaria, de los cuales $56 \%$ representó al sexo femenino y $44 \%$ al sexo masculino. El rango de edad de los menores participantes fue de 10 a 12 años, con una media de 10.88 y una desviación estándar de 0.086.

La tabla 1 muestra el análisis de las escalas que conforman el instrumento, donde es posible apreciar que cada una de ellas arrojó un alfa de Cronbach superior a 0.70 , por lo que se asume que estas presentan un considerable grado de confiabilidad. 
Tabla 1. Análisis y confiabilidad de las escalas/ítems del instrumento

\begin{tabular}{|c|c|c|c|c|c|c|}
\hline Escala/Ítem & $N$ & Min. & Máx. & Media & DE & Alfa \\
\hline $\begin{array}{l}\text { Hábitos de consumo: acceso y } \\
\text { uso }\end{array}$ & & & & & & 0.82 \\
\hline Uso Internet desde el hogar. & 290 & 1 & 5 & 3.85 & 1.87 & \\
\hline $\begin{array}{l}\text { Uso Internet desde una } \\
\text { computadora, laptop o tableta. }\end{array}$ & 290 & 1 & 5 & 2.89 & 1.15 & \\
\hline $\begin{array}{l}\text { Uso Internet con teléfono celular } \\
\text { (smartphone). }\end{array}$ & 290 & 1 & 5 & 4.11 & 1.83 & \\
\hline $\begin{array}{l}\text { Uso Internet desde cualquier } \\
\text { lugar (escuela, cibercafé, casa de } \\
\text { un amigo, casa de un familiar, } \\
\text { en lugares con conexión gratis). }\end{array}$ & 290 & 1 & 5 & 4.04 & 1.79 & \\
\hline $\begin{array}{l}\text { Uso Internet en cualquier lugar } \\
\text { desde mi celular. }\end{array}$ & 290 & 1 & 5 & 4.14 & 3.23 & \\
\hline Uso Internet todos los días. & 290 & 1 & 5 & 4.46 & 1.35 & \\
\hline $\begin{array}{l}\text { Cuando uso Internet visito } \\
\text { páginas de deportes, juegos, } \\
\text { música, noticias de artistas, } \\
\text { páginas de adultos, concursos, } \\
\text { humor y risa. }\end{array}$ & 290 & 1 & 5 & 2.89 & 1.09 & \\
\hline $\begin{array}{l}\text { Cuando uso Internet descargo } \\
\text { música, películas y series de tv. }\end{array}$ & 290 & 1 & 5 & 2.66 & 1.84 & \\
\hline $\begin{array}{l}\text { Cuando uso Internet busco } \\
\text { información para mis tareas } \\
\text { escolares. }\end{array}$ & 290 & 1 & 5 & 3.98 & 1.20 & \\
\hline $\begin{array}{l}\text { Cuando uso Internet es solo para } \\
\text { redes sociales (WhatsApp, } \\
\text { Facebook, Instagram, Twitter, } \\
\text { Snapchat, YouTube, Skype u } \\
\text { otra). }\end{array}$ & 290 & 1 & 5 & 3.86 & 1.24 & \\
\hline $\begin{array}{l}\text { Cuando uso Internet es solo para } \\
\text { correo electrónico }(e-m a i l) \text {. }\end{array}$ & 290 & 1 & 5 & 1.09 & 1.88 & \\
\hline $\begin{array}{l}\text { Cuando uso Internet se abren } \\
\text { páginas para adultos sin querer. }\end{array}$ & 290 & 1 & 5 & 1.67 & 1.04 & \\
\hline $\begin{array}{l}\text { Me gusta visitar páginas de } \\
\text { adultos cuando nadie me ve. }\end{array}$ & 290 & 1 & 5 & 1.89 & 1.14 & \\
\hline $\begin{array}{l}\text { Es divertido ver páginas para } \\
\text { adultos cuando nadie me ve. }\end{array}$ & 290 & 1 & 5 & 1.62 & 1.09 & \\
\hline $\begin{array}{l}\text { Cuando uso Internet veo peleas } \\
\text { de estudiantes en línea. }\end{array}$ & 290 & 1 & 5 & 1.44 & 1.36 & \\
\hline
\end{tabular}




\begin{tabular}{|c|c|c|c|c|c|c|}
\hline $\begin{array}{l}\text { Cuando uso Internet se abren } \\
\text { páginas de peleas de jóvenes. }\end{array}$ & 290 & 1 & 5 & 1.12 & 1.75 & \\
\hline $\begin{array}{l}\text { Me divierte ver videos de } \\
\text { personas hacienda bromas } \\
\text { pesadas a otras. }\end{array}$ & 290 & 1 & 5 & 3.23 & 1.18 & \\
\hline $\begin{array}{l}\text { Me divierte ver hacer cosas } \\
\text { extremas a otras personas. }\end{array}$ & 290 & 1 & 5 & 2.74 & 1.15 & \\
\hline $\begin{array}{l}\text { Me agrada ver videos con } \\
\text { contenido para adultos cuando } \\
\text { nadie me ve. }\end{array}$ & 290 & 1 & 5 & 1.25 & 1.05 & \\
\hline $\begin{array}{l}\text { Cuando uso Internet me } \\
\text { aparecen videos de personas } \\
\text { teniendo relaciones sexuales. }\end{array}$ & 290 & 1 & 5 & 1.15 & 1.83 & \\
\hline $\begin{array}{l}\text { Me molesta ver páginas con } \\
\text { contenido para adultos. }\end{array}$ & 290 & 1 & 5 & 2.25 & 1.04 & \\
\hline Socialización & & & & & & 0.87 \\
\hline $\begin{array}{l}\text { Me comunico con mis amigos de } \\
\text { la escuela por redes sociales } \\
\text { (WhatsApp, Facebook, } \\
\text { Instagram, Twitter, Snapchat, } \\
\text { YouTube, Skype u otra). }\end{array}$ & 290 & 1 & 5 & 4.02 & 1.18 & \\
\hline $\begin{array}{l}\text { Hablo con mis compañeros de la } \\
\text { escuela por redes sociales de } \\
\text { tareas escolares. }\end{array}$ & 290 & 1 & 5 & 3.89 & 1.96 & \\
\hline $\begin{array}{l}\text { Me pongo de acuerdo con mis } \\
\text { amigos para hacer trabajos de la } \\
\text { escuela. }\end{array}$ & 290 & 1 & 5 & 3.88 & 1.84 & \\
\hline $\begin{array}{l}\text { Me pongo de acuerdo con mis } \\
\text { amigos para salir de paseo. }\end{array}$ & 290 & 1 & 5 & 3.45 & 1.08 & \\
\hline $\begin{array}{l}\text { Me comunico con familiares por } \\
\text { redes sociales con los que no } \\
\text { tengo mucho trato. }\end{array}$ & 290 & 1 & 5 & 3.12 & 1.00 & \\
\hline $\begin{array}{l}\text { Uso redes sociales solo para } \\
\text { enterarme de lo que sucede en la } \\
\text { escuela. }\end{array}$ & 290 & 1 & 5 & 3.33 & 1.04 & \\
\hline $\begin{array}{l}\text { Uso redes sociales para conocer } \\
\text { nuevos amigos. }\end{array}$ & 290 & 1 & 5 & 3.96 & 1.14 & \\
\hline $\begin{array}{l}\text { Me divierte conocer a nuevas } \\
\text { personas por redes sociales. }\end{array}$ & 290 & 1 & 5 & 3.12 & 1.90 & \\
\hline $\begin{array}{l}\text { Uso redes sociales para hablar } \\
\text { con personas que no conozco } \\
\text { físicamente. }\end{array}$ & 290 & 1 & 5 & 2.86 & 1.09 & \\
\hline $\begin{array}{l}\text { Me envían solicitudes de } \\
\text { amistad por redes sociales } \\
\text { personas que no conozco. }\end{array}$ & 290 & 1 & 5 & 2.72 & 1.03 & \\
\hline
\end{tabular}




\section{Revista Iberoamericana de las Ciencias Sociales y Humanísticas}

ISSN: $2395-7972$

\begin{tabular}{|c|c|c|c|c|c|c|}
\hline $\begin{array}{l}\text { Me gusta platicar con personas } \\
\text { desconocidas con buen tema de } \\
\text { conversación. }\end{array}$ & 290 & 1 & 5 & 3.05 & 1.18 & \\
\hline $\begin{array}{l}\text { Me gusta platicar con personas } \\
\text { mayores porque me enseñan } \\
\text { cosas. }\end{array}$ & 290 & 1 & 5 & 3.10 & 1.05 & \\
\hline $\begin{array}{l}\text { Se me hace interesante hablar } \\
\text { con personas mayores que yo. }\end{array}$ & 290 & 1 & 5 & 2.25 & 1.89 & \\
\hline $\begin{array}{l}\text { Me parece aburrido hablar con } \\
\text { personas mayores que yo. }\end{array}$ & 290 & 1 & 5 & 3.21 & 1.25 & \\
\hline $\begin{array}{l}\text { Evito hablar con personas } \\
\text { mayores que yo. }\end{array}$ & 290 & 1 & 5 & 3.12 & 1.09 & \\
\hline Evito hablar con desconocidos. & 290 & 1 & 5 & 3.25 & 1.16 & \\
\hline $\begin{array}{l}\text { Comento en redes sociales } \\
\text { estados de otras personas para } \\
\text { que me hablen. }\end{array}$ & 290 & 1 & 5 & 1.14 & 1.10 & \\
\hline $\begin{array}{l}\text { Me divierte leer comentarios de } \\
\text { estados o publicaciones de otras } \\
\text { personas por redes sociales. }\end{array}$ & 290 & 1 & 5 & 1.12 & 1.99 & \\
\hline $\begin{array}{l}\text { Comparto con mis amigos } \\
\text { publicaciones o estados que me } \\
\text { dan risa. }\end{array}$ & 290 & 1 & 5 & 1.89 & 1.05 & \\
\hline $\begin{array}{l}\text { Hago memes graciosos de } \\
\text { amigos para reírnos. }\end{array}$ & 290 & 1 & 5 & 1.19 & 1.85 & \\
\hline $\begin{array}{l}\text { Comparto memes de amigos por } \\
\text { redes sociales para divertirnos. }\end{array}$ & 290 & 1 & 5 & 2.11 & 1.24 & \\
\hline $\begin{array}{l}\text { Mis amigos me comparten por } \\
\text { redes sociales memes, } \\
\text { publicaciones y estados de otros } \\
\text { compañeros de clase. }\end{array}$ & 290 & 1 & 5 & 1.67 & 1.09 & \\
\hline $\begin{array}{l}\text { Recibo contenido para adultos } \\
\text { por redes sociales de } \\
\text { compañeros de clase o amigos. }\end{array}$ & 290 & 1 & 5 & 1.83 & 1.14 & \\
\hline $\begin{array}{l}\text { Recibo contenido para adultos } \\
\text { por redes sociales de personas } \\
\text { que no conozco. }\end{array}$ & 290 & 1 & 5 & 1.33 & 1.07 & \\
\hline $\begin{array}{l}\text { Recibo contenidos para adultos } \\
\text { por redes sociales de algún } \\
\text { familiar. }\end{array}$ & 290 & 1 & 5 & 1.29 & 1.87 & \\
\hline Derechos fundamentales & & & & & & 0.84 \\
\hline $\begin{array}{l}\text { Cuando uso aplicaciones y redes } \\
\text { sociales me piden datos } \\
\text { personales. }\end{array}$ & 290 & 1 & 5 & 1.89 & 1.11 & \\
\hline $\begin{array}{l}\text { Tengo perfil o cuenta en redes } \\
\text { sociales. }\end{array}$ & 290 & 1 & 5 & 2.89 & 1.14 & \\
\hline
\end{tabular}




\section{Revista Iberoamericana de las Ciencias Sociales y Humanísticas}

ISSN: $2395-7972$

\begin{tabular}{|c|c|c|c|c|c|}
\hline $\begin{array}{l}\text { Cuando estoy en Internet digo lo } \\
\text { que pienso. }\end{array}$ & 290 & 1 & 5 & 1.89 & 1.88 \\
\hline $\begin{array}{l}\text { Cuando uso Internet veo lo que } \\
\text { quiero. }\end{array}$ & 290 & 1 & 5 & 2.77 & 1.99 \\
\hline $\begin{array}{l}\text { Puedo usar el Internet cuando } \\
\text { quiero. }\end{array}$ & 290 & 1 & 5 & 3.36 & 1.18 \\
\hline $\begin{array}{l}\text { Cuando estoy en Internet mis } \\
\text { papás ven lo que veo. }\end{array}$ & 290 & 1 & 5 & 2.68 & 1.09 \\
\hline $\begin{array}{l}\text { Cuando uso Internet mis papás } \\
\text { no ven lo que yo veo. }\end{array}$ & 290 & 1 & 5 & 2.25 & 1.15 \\
\hline $\begin{array}{l}\text { Mis papás me prohíben usar el } \\
\text { Internet cuando no están en casa. }\end{array}$ & 290 & 1 & 5 & 1.17 & 1.89 \\
\hline $\begin{array}{l}\text { Mis papás me enseñan a usar el } \\
\text { Internet. }\end{array}$ & 290 & 1 & 5 & 1.22 & 1.02 \\
\hline $\begin{array}{l}\text { Mis papás me preguntan cómo } \\
\text { usar Internet. }\end{array}$ & 290 & 1 & 5 & 1.89 & 1.14 \\
\hline $\begin{array}{l}\text { Conozco los riesgos y peligros } \\
\text { de Internet. }\end{array}$ & 290 & 1 & 5 & 2.26 & 1.04 \\
\hline $\begin{array}{l}\text { Mis papás me advierten de los } \\
\text { riesgos y peligros de usar } \\
\text { Internet }\end{array}$ & 290 & 1 & 5 & 2.89 & 1.11 \\
\hline $\begin{array}{l}\text { Me expreso libremente en } \\
\text { Internet. }\end{array}$ & 290 & 1 & 5 & 2.78 & 1.92 \\
\hline $\begin{array}{l}\text { Mis papás me preguntan lo que } \\
\text { hago en Internet }\end{array}$ & 290 & 1 & 5 & 2.94 & 1.13 \\
\hline $\begin{array}{l}\text { Mis papás ponen claves y } \\
\text { contraseñas para que no use el } \\
\text { Internet. }\end{array}$ & 290 & 1 & 5 & $2 . .39$ & $1 . .06$ \\
\hline $\begin{array}{l}\text { Mis papás quitaron el Internet en } \\
\text { casa. }\end{array}$ & 290 & 1 & 5 & 2.24 & 1.02 \\
\hline $\begin{array}{l}\text { Mis papás me castigan con el } \\
\text { uso de Internet. }\end{array}$ & 290 & 1 & 5 & 1.25 & 1.86 \\
\hline $\begin{array}{l}\text { Mis papás me ayudan a buscar } \\
\text { información en Internet para mis } \\
\text { tareas. }\end{array}$ & 290 & 1 & 5 & 3.34 & 1.15 \\
\hline $\begin{array}{l}\text { Tengo claves y contraseñas para } \\
\text { usar el Internet }\end{array}$ & 290 & 1 & 5 & 3.12 & 1.04 \\
\hline $\begin{array}{l}\text { No tengo las claves y } \\
\text { contraseñas para usar el Internet }\end{array}$ & 290 & 1 & 5 & 2.26 & 1.88 \\
\hline
\end{tabular}

Fuente: Elaboración propia con base en Contreras y León (2019), León et al. (2014, 2015), León et al. (2016) y Contreras (2019a, 2019c). 
La tabla 2 presenta los resultados de la adecuación de KMO y el test de esfericidad de Barlett, donde fue posible observar la pertinencia y factibilidad de realizar el AFE, al obtener datos consistentes y adecuados, según la teoría estadística.

Tabla 2. Test de esfericidad de Barlett y prueba de KMO

\begin{tabular}{|c|c|c|}
\hline \multicolumn{2}{|l|}{ Medida de adecuación muestral de KMO } & 0.861 \\
\hline Prueba de esfericidad de & Ji al cuadrado aproximado & 2246,341 \\
Barlett & Gl & 64 \\
& Sig. & .000 \\
\hline
\end{tabular}

Fuente: Elaboración propia

\section{Análisis del modelo estructural}

La figura 1 muestra el modelo estructural del estudio. En él se puede apreciar que el factor Socialización está formado por las escalas de Interacción virtual con los pares con un puntaje factorial $(\mathrm{PF}=0.79)$, Interacción virtual con los padres $(\mathrm{PF}=.74)$, Interacción virtual con personas desconocidas $(\mathrm{PF}=0.68)$ e Interacción virtual con personas conocidas $(\mathrm{PF}=$ 0.66). Asimismo, el factor Hábitos de consumo se formó con las escalas de Acceso involuntario a contenidos inapropiados $(\mathrm{PF}=0.62)$, Acceso involuntario a conductas inapropiadas por terceras personas $(\mathrm{PF}=0.67)$, Acceso voluntario a contenidos inapropiados $(\mathrm{PF}=0.27)$ y Acceso voluntario a conductas inapropiadas por terceras personas $(\mathrm{PF}=0.29)$. El factor de Derechos fundamentales se formó con las escalas de Protección de los menores contra el abuso $(\mathrm{PF}=0.44)$, Acceso a la información $(\mathrm{PF}=0.52)$, Libre expresión y asociación $(\mathrm{PF}=0.56)$, Protección a la intimidad del menor $(\mathrm{PF}=0.62) \mathrm{y}$, finalmente, con la escala de Involucramiento de los padres en la digitalización $(\mathrm{PF}=0.72)$.

En el modelo es posible ver que el factor de Socialización está impactando de forma directa y positiva con el factor de Hábitos de consumo del menor con un coeficiente estructural $(\mathrm{CE}=0.89)$. Así pues, los hábitos de consumo tienen un efecto directo y fuerte con los derechos fundamentales $(\mathrm{CE}=0.68)$; a la vez que los derechos de los menores están siendo afectados y vulnerados principalmente por el acceso involuntario a contenidos inapropiados $(\mathrm{CE}=0.24)$, acceso involuntario a conductas inapropiadas por terceras personas 
$(\mathrm{CE}=0.49)$, acceso voluntario a contenidos inapropiados $(\mathrm{CE}=0.44)$ y acceso voluntario a conductas inapropiadas por terceras personas $(\mathrm{CE}=0.27)$. Como se puede apreciar, cada una de las cargas de los puntajes factoriales, así como los coeficientes estructurales, fueron altamente significativos.

Por otra parte, los estadísticos adoptados fueron el índice de ajuste normado de Bentler-Bonett $(\mathrm{BBNFI}=0.89)$, índice de ajuste no normado $(\mathrm{NNFI}=0.92)$ y el índice de ajuste comparativo $(\mathrm{CFI}=0.94)$. Los indicadores en cada una de las pruebas debía ser superior a 0.90; por su parte, la raíz cuadrada del cuadrado medio del error de aproximación (RMSEA) fue de 0.05, es decir, un resultado dentro de los parámetros aceptables, mientras que la ji al cuadrado fue de 33.68 y 32 grados de libertad (gl), con 0.00 de probabilidad asociada y, finalmente, una $R^{2}$ de 0.36 , lo cual significa que el modelo de ecuaciones estructurales explica en su conjunto $36 \%$ de la varianza de factores de riesgo asociados en los derechos fundamentales de los menores en sus procesos de socialización por redes sociales.

Figura 1. Modelo estructural factores que predicen el riesgo de los derechos de los menores en la era digital

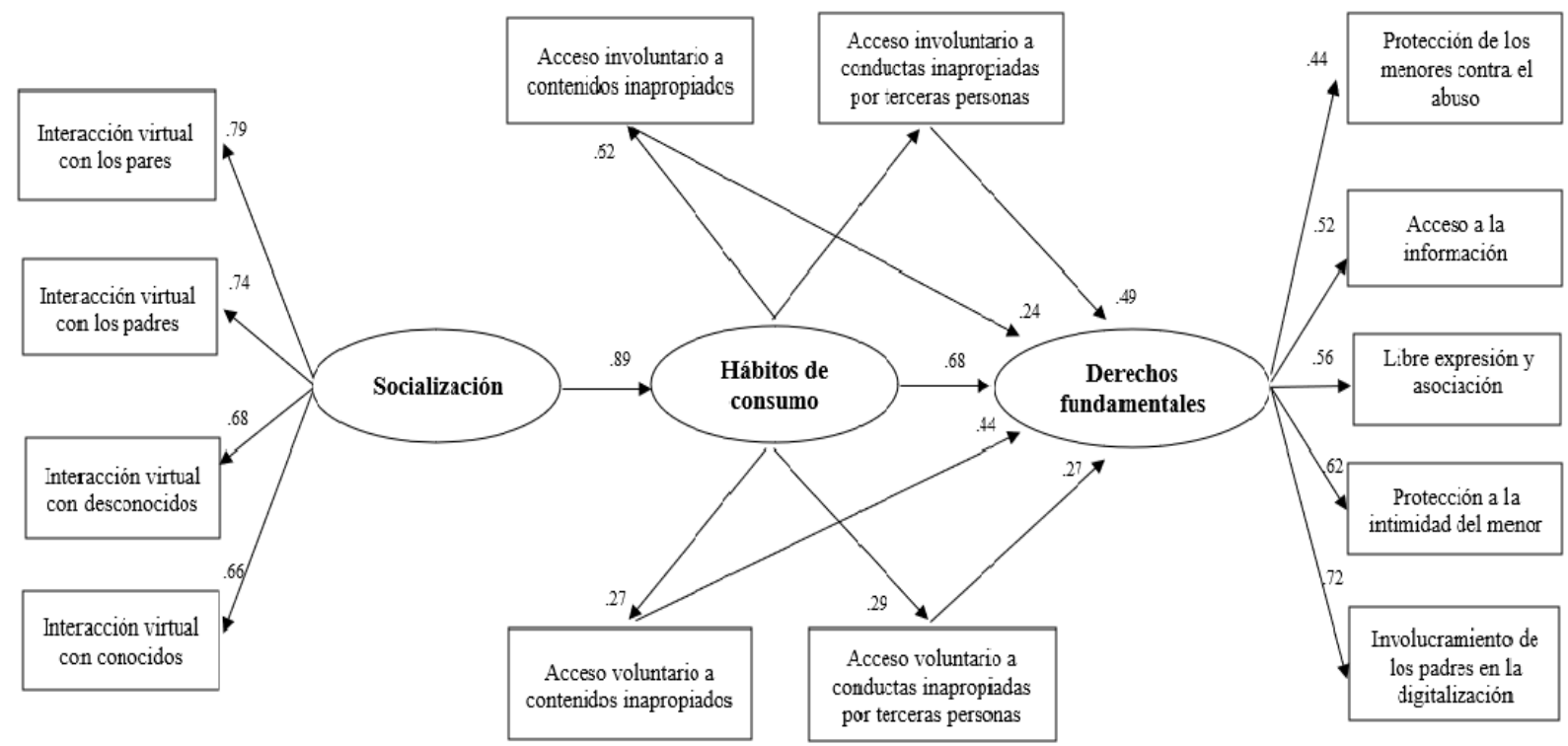

$\mathrm{N}=290, \mathrm{X}^{2}=33.68 ; \mathrm{gl}=32 ; \mathrm{p}=.00 ; \mathrm{BBNFI}:=.89 ; \mathrm{BENNFI}:=.92 \mathrm{CFI}:=.94 ; \mathrm{RMSEA}=.05 ; \mathrm{R}^{2} .36$.

Fuente: Elaboración propia 


\section{Discusión}

Para advertir sobre los efectos positivos y negativos que predicen y explican los riesgos en los derechos de los niños y niñas de educación primaria, fue necesario realizar diversas pruebas estadísticas, como el test de KMO y la prueba de esfericidad de Barlett, mediante la cual fue posible observar la adecuación y pertinencia de los factores propuestos para el AFE y el AFC. De acuerdo con el modelo estructural, el aporte significativo de esta investigación consistió en especificar los factores que influyen y predicen el riesgo en el uso de redes sociales frente a los derechos fundamentales de los menores en sus procesos de interacción.

En una primera radiografía, según el estudio presentado por Contreras y Campa (2017), se pudo evidenciar que el modelo propuesto por los autores daba cuenta de que los adolescentes muestran una tendencia de acceso y uso de Internet para fines de interacción y socialización. Adicionalmente, en el modelo presentado se evidenció que los jóvenes en su mayoría prefieren el uso de Internet para compartir sus experiencias con sus iguales (Contreras y Campa, 2017).

En este escenario, se pudo constatar que los estudiantes de educación primaria revelaron una tendencia muy similar al reflejar que el factor de socialización tuvo un impacto significativo y directo con los hábitos de consumo como parte del acceso y uso de Internet, por lo que se deduce que, a partir de los procesos de socialización, mediante la interacción con sus iguales (pares), sus padres, personas conocidas y desconocidas, los menores acceden y usan esta herramienta afectando de forma positiva algunos de sus derechos fundamentales, tales como el acceso a la información, libre expresión y asociación; pero también con un efecto directo en la vulneración de la protección de la intimidad del menor cuando no existe un involucramiento por parte de los padres o tutores en la digitalización de niños y niñas.

Por su parte, Maffesoli (2004) manifiesta que los procesos de sociabilidad están presentes en el relajo, los juegos y las bromas. Bajo esta perspectiva, es necesario aclarar que los estudiantes no solo comparten experiencias de ocio y entretenimiento, como menciona Maffesoli (2004), sino que parte de sus procesos de socialización refieren a obligaciones escolares y de carácter informativo, tal y como se evidenció en este estudio. De acuerdo con Huertas (2012), en un contexto más mediado por las tecnologías móviles y el acceso a Internet, los procesos de socialización reconfiguran los marcos para la interacción social, lo 
que acarrea nuevos retos para la convivencia y la relación de los jóvenes en sus procesos vivenciales.

Así pues, contrario a lo que manifiestan Espinoza y Rodríguez (2017), quienes afirman que los niños y niñas siguen prefiriendo la convivencia de manera presencial, ya que los sujetos de su estudio manifestaron estar más habituados a desarrollar lazos de amistad de manera personal, el modelo estructural aquí ejecutado dejó en claro que los menores prefieren las interacciones por medio de redes sociales y dispositivos móviles, lo cual es comprensible al analizar la edad de los participantes, lo que los imposibilita a ejercer plena libertad para salir de casa e interactuar físicamente con sus pares si así lo desean.

Es importante señalar que este estudio presenta algunas implicaciones y limitaciones al no considerar: 1) la totalidad de los derechos de la infancia que plantean la Cepal y Unicef (2014) en la era digital del menor; 2) muestras de poblaciones más amplias que permitan extrapolar los resultados a otras latitudes, y 3) el modelo estructural propuesto presentó algunas variaciones en los pesos y coeficientes factoriales, lo que podría afectar en una explicación parcial del este.

Resulta imprescindible señalar, de igual forma, las fortalezas del estudio: 1) el instrumento que se utilizó para recabar información es confiable y puede ser aplicado en sujetos con una edad aproximada de 10 y 12 años; 2) se propuso un modelo estructural estadístico que diera cuenta de los derechos que están siendo afectados por factores que predicen y explican el riesgo en los hábitos de consumo y uso de redes sociales por menores, y finalmente 3) provee a la literatura científica modelos predictivos que permitan comprender y explicar las diversas problemáticas sociales que giran entorno al campo de las ciencias sociales.

Por lo anterior, algunas consideraciones para próximos estudios es incluir muestras más amplias de diferentes contextos territoriales y áreas socioeconómicas altas que permitan realizar comparaciones del modelo propuesto. 


\section{Conclusión}

Como parte del objetivo central del estudio, se obtuvo un modelo explicativo que relaciona los procesos de socialización de los estudiantes de educación primaria en sus hábitos de consumo, así como la relación de conductas inapropiadas por terceras personas consideradas factores de riesgo en los niños y niñas, y que vulneran sus derechos fundamentales como la protección contra el abuso, protección a la intimidad, acceso a la información, libre expresión y asociación.

El modelo estructural evidenció que los hábitos de consumo en el acceso y uso de Internet tuvieron un impacto directo con los derechos fundamentales de los menores; es decir, los jóvenes, cuando acceden a esta herramienta con fines de socialización, están más propensos a ver, ya sea de manera voluntaria o involuntaria, contenidos no apropiados para menores, así como están más expuestos a conductas inapropiadas por terceras personas. Por esta razón, se debe hacer énfasis y atender puntualmente los derechos fundamentales que están siendo afectados por sus hábitos de consumo y uso en la digitalización de los menores. De esta manera se protegerían los derechos de niños y niñas en un mundo más conectado, previniendo riesgos en la digitalización de los menores, sin que ello suponga una pérdida en sus derechos y libertades en el acceso de estas herramientas y dispositivos tecnológicos.

En este contexto, uno de los retos más importantes que debe imperar en la sociedad digital, donde participan legisladores, padres, profesionales e investigadores, debe ser sin lugar a duda salvaguardar y preservar los derechos de los menores en el uso de estas herramientas tecnológicas en sus procesos de socialización.

\section{Agradecimientos}

Este proyecto fue realizado gracias al apoyo del Programa para el Desarrollo Profesional Docente (Prodep) (Tipo superior). Secretaría de Educación Pública (SEP). Referencia del proyecto 0704256. Unison-PTC 275. 


\section{Referencias}

Bernal, C. y Angulo, F. (2012). Interacciones de los jóvenes andaluces en las redes sociales. Comunicar, 20(40), 25-30. Recuperado de http://dx.doi.org/10.3916/C40-2013-0202.

Bringué, X. y Sádaba, C. (2010). La Generación Interactiva en España. Niños y adolescentes ante las pantallas. Madrid, España: Ariel y Fundación Telefónica en colaboración con Editorial Planeta. Recuperado de http://dadun.unav.edu/handle/10171/17155.

Bringué, X., Sádaba, C. y Rodríguez, J. (2008). La Generación Interactiva frente a un nuevo escenario de comunicación: Retos sociales y educativos. Navarra, España: Consejo Audiovisual de Navarra. Recuperado de https://dadun.unav.edu/bitstream/10171/17122/1/ESTUDIO_GENERACION_INTE RACTIVA.pdf.

Campa, R. Á. y Contreras, C. R. (2018). Aspectos psicosociales asociados en el proceso de inclusión educativa durante la infancia intermedia. Infancias Imágenes, 17(1), 9-24. Recuperado de https://doi.org/10.14483/16579089.12535

Celaya, J. (2008). La Empresa en la WEB 2.0. España: Editorial Grupo Planeta.

Chapman, W. (2015.) El concepto de sociabilidad como referente del análisis histórico. Investigación $\quad y \quad$ Desarrollo, 23(1). Recuperado de http://dx.doi.org/10.14482/indes.23.1.6040.

Comisión Económica para América Latina y el Caribe [Cepal]. (31 de octubre 2014). El uso seguro de las TIC puede ayudar a niños y adolescentes a ejercer mejor sus derechos. Comunicado de prensa. Recuperado de https://www.cepal.org/ptbr/comunicados/uso-seguro-de-las-tic-puede-ayudar-ninos-y-adolescentes-ejercermejor-sus-derechos

Comisión Económica para América Latina y el Caribe [Cepal] y Fondo de las Naciones Unidas para la Infancia [Unicef]. (2014). Derechos de la infancia en la era digital. Desafíos: Boletín de la Infancia y Adolescencia sobre el Avance de los Objetivos de Desarrollo del Milenio, (18). Recuperado de https://repositorio.cepal.org/bitstream/handle/11362/37139/1/S1420568_es.pdf.

Contreras, C. R. (2019a). Validación de la escala de derechos fundamentales y uso de redes sociales en menores de escuelas primarias públicas en México. En de Vicente, A. M. 
y Sierra, J. (coords.), Aproximación periodística y educomunicativa al fenómeno de las redes sociales. México: McGraw-Hill.

Contreras, C. R. (2019b). Investigación de las competencias digitales y uso de tecnologías en la práctica del profesor universitario. En Roig, R. (ed.), Investigación e innovación en la enseñanza superior. Nuevos contextos, nuevas ideas (pp. 104-112). Barcelona, España: Editorial Octaedro. Recuperado de https://rua.ua.es/dspace/bitstream/10045/98874/1/Investigacion-e-innovacion-en-laES_010.pdf.

Contreras, C. R. (2019c). Proceso de socialización en jóvenes de secundarias en el acceso y uso de Internet a partir de un modelo estructural. Educación, Lenguaje y Sociedad, 16(16) 1-28. Recuperado de https://cerac.unlpam.edu.ar/index.php/els/article/view/3864/3921.

Contreras, C. R. y Campa, R. (2017). Caracterización del perfil de los estudiantes de secundarias en el acceso y uso de internet a partir de las TIC. EDUTEC, Revista Electrónica de Tecnología Educativa, 61. Recuperado de http://www.edutec.es/revista/index.php/edutec-e/article/view/941.

Contreras, C. R. y León, G. A. (2019) Análisis factorial de un modelo de socialización y confianza en la dependencia de Internet. Revista Electrónica de Investigación Educativa. 21(e25), 1-13. Recuperado de https://doi.org/10.24320/redie.2019.21.e25.2112.

Douglas, M. and Isherwood, B. (1996). The World of Goods: Towards an Anthropology of Consumption. London, England: Routledge.

Espinoza, L. y Rodríguez, R. (2017). El uso de tecnologías como factor del desarrollo socioafectivo en niños y jóvenes estudiantes en el noroeste de México. RICSH Revista Iberoamericana de las Ciencias Sociales y Humanísticas, 6(11). Recuperado de https://doi.org/10.23913/ricsh.v6i11.113.

Fernández, A. (2016). La protección de los derechos fundamentales de los menores en Internet desde la perspectiva europea. Ius et Praxis, 22(1). Recuperado de http://dx.doi.org/10.4067/S0718-00122016000100011.

Fondo de las Naciones Unidas para la Infancia [Unicef]. (2006). Convención sobre los derechos del niño. Madrid, España: Fondo de las Naciones Unidas para la Infancia. Recuperado en https://www.unicef.es/sites/www.unicef.es/files/\%20CDN_06.pdf. 
Fondo de las Naciones Unidas para la Infancia [Unicef]. (2014). Vulnerabilidad y exclusión en la infancia. Madrid, España: Fondo de las Naciones Unidas para la Infancia. Recuperado de unicef.es/sites/unicef.es/files/libro_03_web.pdf.

Fondo de las Naciones Unidas para la Infancia [Unicef]. (2016). Los Derechos de la Infancia y el Internet. Recuperado de https://www.unicef.org/csr/files/Spanish_UNICEF_GUARDIAN_publication.pdf

Fondo de las Naciones Unidas para la Infancia [Unicef]. (2017). El estado mundial de la infancia. Niños en un mundo digital. Nueva York, Estados Unidos: División de Comunicaciones de Unicef. Recuperado de https://www.unicef.org/spanish/publications/files/SOWC_2017_Summary_Es_WE B.pdf.

Fondo de las Naciones Unidas para la Infancia [Unicef]. (2018). Los derechos de la infancia y la adolescencia en México. Ciudad de México, México: Fondo de las Naciones Unidas para la Infancia. Recuperado de https://www.unicef.org/mexico/media/1791/file/SITAN-UNICEF.pdf.

Gallego, S. (2011). Redes sociales y desarrollo humano. Barataria.Revista CastellanoManchega de Ciencias Sociales (12), 113-121. https://www.redalyc.org/pdf/3221/322127622007.pdf

González, B. (2014). La teoría de redes sociales y las políticas públicas. Una aproximación al debate teórico y a las posibilidades de intervención en realidades sociales. FORUM, Revista Departamento de Ciencia Política, (6). Recuperado de https://revistas.unal.edu.co/index.php/forum/article/view/52968.

Hernández, C. y Alcoceba, J. A. (2015): Socialización virtual, multiculturalidad y riesgos de los adolescentes latinoamericanos en España, Icono 14, 13(2), 116-141 https://doi.org/10.7195/ri14.v13i2.787

Hernández, R., Fernández, C. y Baptista, P. (2010). Metodología de la investigación social

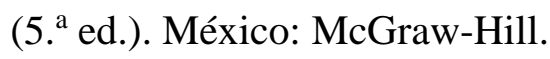

Huertas, A. (2012). Procesos de sociabilidad e identidades en Internet: una aproximación a partir del estudio de contextos sociales multiculturales juveniles en España. En Cogo, D., ElHajji, M. y Huertas, A. (coords.), Diásporas, migrações, tecnologias da comunicação e identidades transnacionais. Barcelona, España: InComUAB. 
Hütt, H. (2012). Las redes sociales: una nueva herramienta de difusión Reflexiones, 91(2), 121-128.

Recuperado de https://revistas.ucr.ac.cr/index.php/reflexiones/article/view/1513.

Instituto Nacional de Estadística [INE]. (2019). Encuesta sobre Equipamiento y Uso de Tecnologías de Información y Comunicación en los Hogares Año 2019. España: Instituto Nacional de Estadística. Recuperado de https://www.ine.es/prensa/tich_2019.pdf.

Instituto Nacional de Estadística y Geografía [Inegi]. (16 de mayo de 2018). Estadísticas a propósito del día mundial del internet (17 de mayo) datos nacionales. Comunicado de prensa Núm. 252/1. Recuperado de https://www.inegi.org.mx/contenidos/saladeprensa/aproposito/2018/internet2018_N al.pdf.

Instituto Nacional de Estadística y Geografía [Inegi]. (15 de mayo de 2019). Estadísticas a propósito del día mundial del Internet (17 de mayo) datos nacionales. Comunicado de $\begin{array}{llll}\text { prensa Núm. } & \text { 252/19. } & \text { Recuperado }\end{array}$ https://www.inegi.org.mx/contenidos/saladeprensa/aproposito/2019/internet2019_N al.pdf.

León, G., Caudillo, D. Y., Contreras, C. R. y Moreno, E. (2014). Internet seguro y jóvenes de secundaria en México. Hermosillo: Universidad de Sonora.

León, G., Caudillo, R. D., Contreras, C. y Moreno, C. D. (2015). Jóvenes y medios digitales móviles en México. Un estudio de variables asociadas en perspectiva Interdisciplinar (1. ${ }^{\mathrm{a}}$ ed.). México: Pearson Educación.

León, G., Contreras, C. R. y Moreno, D. (2016). Probando modelos interdisciplinares inclusivos en la dependencia de Internet en Jóvenes. Nuevas variables asociadasll. Revista Latina de Comunicación Social, 71, 616-631. Recuperado de http://www.revistalatinacs.org/071/paper/1112/RLCS-paper1112.pdf.

Lloret, S., Ferreres, A., Hernández, A. y Tomás, I. (2014). El análisis factorial exploratorio de los ítems: Una guía práctica, revisada y activada. Anales de Psicología, 30(3), 1151-1169. Recuperado de http://dx.doi.org/10.6018/analesps.30.3.199361.

Lucas, M. A. (1986). El proceso de Socialización: Un enfoque sociológico. Revista Española de Pedagogía, 44(173), 357-370. Recuperado de https://revistadepedagogia.org/wpcontent/uploads/2018/04/3-El-Proceso-de-Socializaci\%C3\%B3n.pdf. 
Maffesoli, M. (2004). El tiempo de las tribus: el ocaso del individualismo en las sociedades posmodernas. Ciudad de México, México: Siglo XXI.

Mejía, E. y Arboleda, M. (2004). Psicografía de los consumidores caleños en los estratos 5 y 6. (proyecto de grado). Universidad Icesi, Santiago de Cali. Recuperado de https://docplayer.es/36932256-Psicografia-de-los-consumidores-calenos-en-losestratos-5-y-6.html.

Muñoz, L. y Antón M. (2017). Estudio de uso y actitudes de consumo de contenidos digitales. España: Observatorio Español de la Economía y la Sociedad Digital. Recuperado de https://www.ontsi.red.es/ontsi/es/content/estudio-de-uso-y-actitudes-de-consumode-contenidos-digitales

Pacheco, A. B., Lozano, G. J. y González, R. (2018). Diagnóstico de utilización de Redes sociales: factor de riesgo para el adolescente. Revista Iberoamericana para la Investigación y el Desarrollo Educativo (RIDE), 8(16). Recuperado de https://doi.org/10.23913/ride.v8i16.334.

Pérez, M. (2005). Aproximación a un estudio sobre vulnerabilidad y violencia familiar. Boletín Mexicano de Derecho Comparado, (113). Recuperado de https://revistas.juridicas.unam.mx/index.php/derechocomparado/article/view/3843/4801\#N3

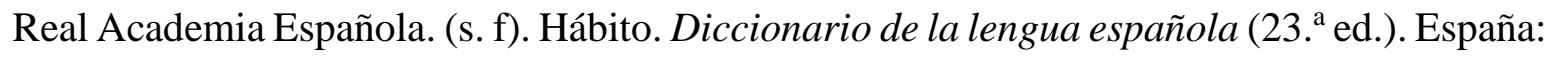
Real Academia Española. Recuperado de http://dle.rae.es/?id=AT3QP6.

Sánchez, D. y Robles, M. A. (2016). Riesgos y potencialidades de la era digital para la infancia y la adolescencia. Revista Educación y Humanismo, 18(31), 186-204. http://dx.doi.org/10.17081/eduhum.18.31.1374.

Secretaría de Educación y Cultura [SEC] (2018). La Unidad de Transparencia de la Secretaria de Educación y Cultura y Servicios Educativos del Estado de Sonora. Recuperado el 08 de octubre 2018 en: http://www.sec-sonora.gob.mx/

Simkin, H. y Becerra, G. (2013). El proceso de socialización. Apuntes para su exploración en el campo psicosocial. Ciencia, Docencia y Tecnología, 24(47), 119-142. Recuperado de https://dialnet.unirioja.es/servlet/articulo?codigo=4696738.

Unión Interparlamentaria y la Organización de las Naciones Unidas [ONU]. (2016). Derechos Humanos. Ginebra, Suiza: Unión Interparlamentaria. Recuperado de https://www.ohchr.org/Documents/Publications/HandbookParliamentarians_SP.pdf. 